\title{
Fuzzy Based Control of Induction Motor for A Four Switch Inverter Topology
}

\author{
Vaisakh.T \\ Post Graduate, Power Electronics and Drives
}

\begin{abstract}
The paper proposes an FLC scheme for a four switch inverter fed induction motor emulating the six switch inverter operation. An induction motor torque control strategy is proposed. The paper proposes a three phase inverter using only four switches rather than six switches, which is conventional approach. By using lesser number of switches the switching losses are reduced to a great extent.. Steady state operation of the induction motor is maintained by PI and fuzzy logic controllers.
\end{abstract}

Keywords: direct torque control (DTC), four-switch/six-switch three-phase inverter (FSTPI/SSTPI)

\section{Introduction}

The major advantages of DTC scheme introduced in the middle of 80's lead to further researches which improved the original DTC strategy yielding better performance.

The areas of focus were mainly torque ripple and switching frequency. To find a solution for mentioned problems, space vector modulation is incorporated. Along with four switch VSI, the disadvantage of this being only complexity in implementing the scheme.

The proposed scheme is equipped for ripple reduction in torque. The steady state oscillations and unwanted forced oscillations can be eliminated by the designed PI controllers.

\section{Circuit Diagram Description}

The AC input is fed to a three phase diode bridge which produces a DC output. The DC is further converted to AC by a four switch three phase inverter topology before feeding to the induction motor. The fuzzy controller makes it possible to control the triggering of the inverter side switches to provide the desired output.

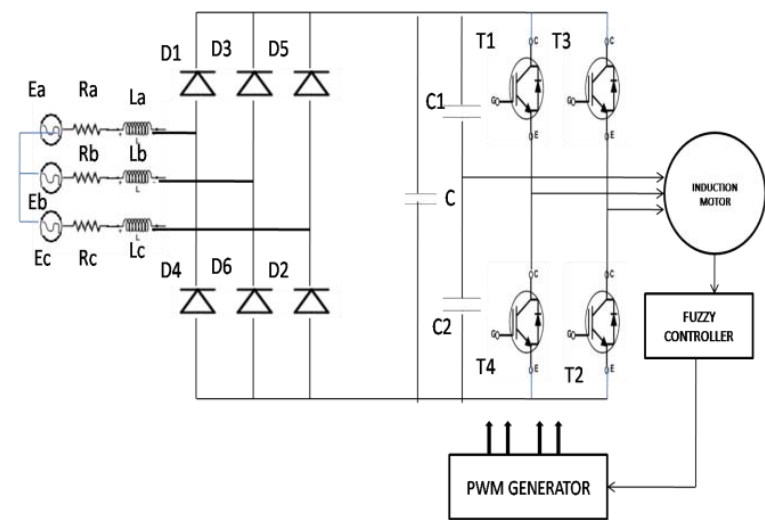

Vector control strategy is widely used in the implementation of four switch three phase inverter. In the six switch topology the active vectors present were six which is now carefully cut down to four in the proposed topology.

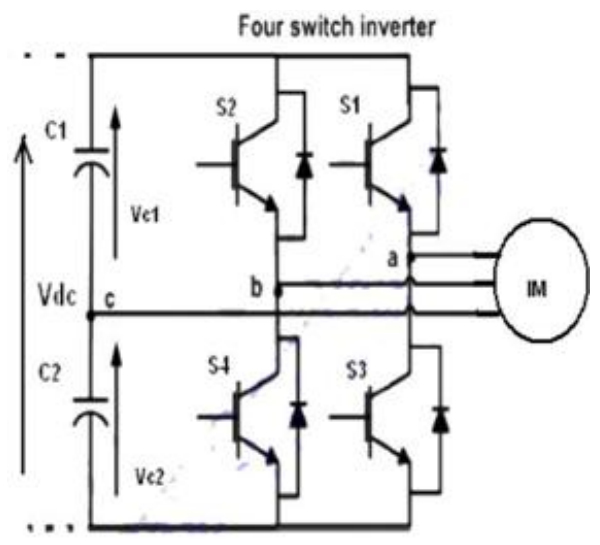

The PWM signal is applied to the switches to obtain the desired switching pattern and hence the desired output. To make this possible we employ the space vector pulse width modulation.

The inverter consists of two capacitance and four switches. The respective voltage across each capacitor is $\mathrm{V}_{\mathrm{c} 1}$ and $\mathrm{V}_{\mathrm{c} 2}$. $\mathrm{V}_{\mathrm{dc}}=\mathrm{V}_{\mathrm{c} 1}+\mathrm{V}_{\mathrm{c} 2}$

In order to switch the switches a small dead time is given between the switchesof the upper and lower switches to ensure no accidental short circuits.

Scheme of scalar modulation which makes use of phase voltages for the assessment and calculation of switching frequency is made use I this topology as the implementation is fairly easy.

\section{Block Diagram}

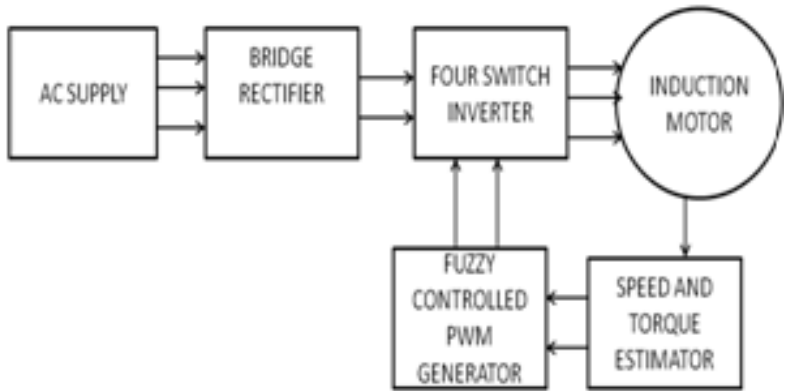

The proposed inverter is used to control the induction motor. Block diagram includes input from power supply, PIC drive

\section{Volume 4 Issue 11, November 2015}




\section{International Journal of Science and Research (IJSR) \\ ISSN (Online): 2319-7064}

Index Copernicus Value (2013): 6.14 | Impact Factor (2014): 5.611

circuit, control algorithm and respective converting circuit at the input side $\mathrm{s}$ well as the load side.

\section{Input Source}

The input given is an AC supply to a diode bridge rectifier. The DC output from the rectifier is fed to the proposed inverter. The output from the control circuit is fed to the inverter which regulated the switches according to the load requirement.

The input to IC and drive circuit is inevitably given from $+5 \mathrm{~V}$ and $+12 \mathrm{~V}$ DC supply.

\section{Rectifier}

A diode bridge rectifier circuit provides satisfactory performance for our application. Around $90 \%$ of rms value of input will be availed at the output of the rectifier. The ripples present at the output of the rectifier circuit due to the operation of the diode will be suitably filtered by the use of capacitor.

\section{Torque Estimator}

A simple PI controller is used for the purpose of torque estimation. Speed error between reference speed and actual speed is obtained and torque is calculated. The calculated torque is fed to the fuzzy controller. We keep the stator flux at a fixed value and vary the stator angle.

\section{Flux Estimator}

Fuzzy logic controller is again responsible for the operation of flux estimation. The input from PI controller as current component is made use to control speed.

The output from the fuzzy logic controller is used to look up the switching table of space vector pulse width modulation.

\section{Induction Motor}

Motors are most widely used for industrial application are induction motors. The most versatile feature about induction motor is its characteristic constant speed fro no load to full load. The speed control mechanisms are usually implemented in DC motors as induction motors are less adaptable for speed control. The rotor rotates in the external field created by the stator and the electrical energy is converted to mechanical energy. That is why it is called a rotating transformer.

\section{Fuzzy Controller}

A fuzzy controller is introduced in the system to assess the correlation between the prevailing condition and the output. This relation is checked using a IF-THEN rule which is common in fuzzy inference systems. The described condition is associated with the conclusion using the rule. The former part mainly refers to the condition while the latter describes the output or the conclusion.

\section{Implication Rule}

The output and input are correlated by the above mentioned rule. The basic sense of fuzzy logic is made in use here.

\section{Experimental Result}
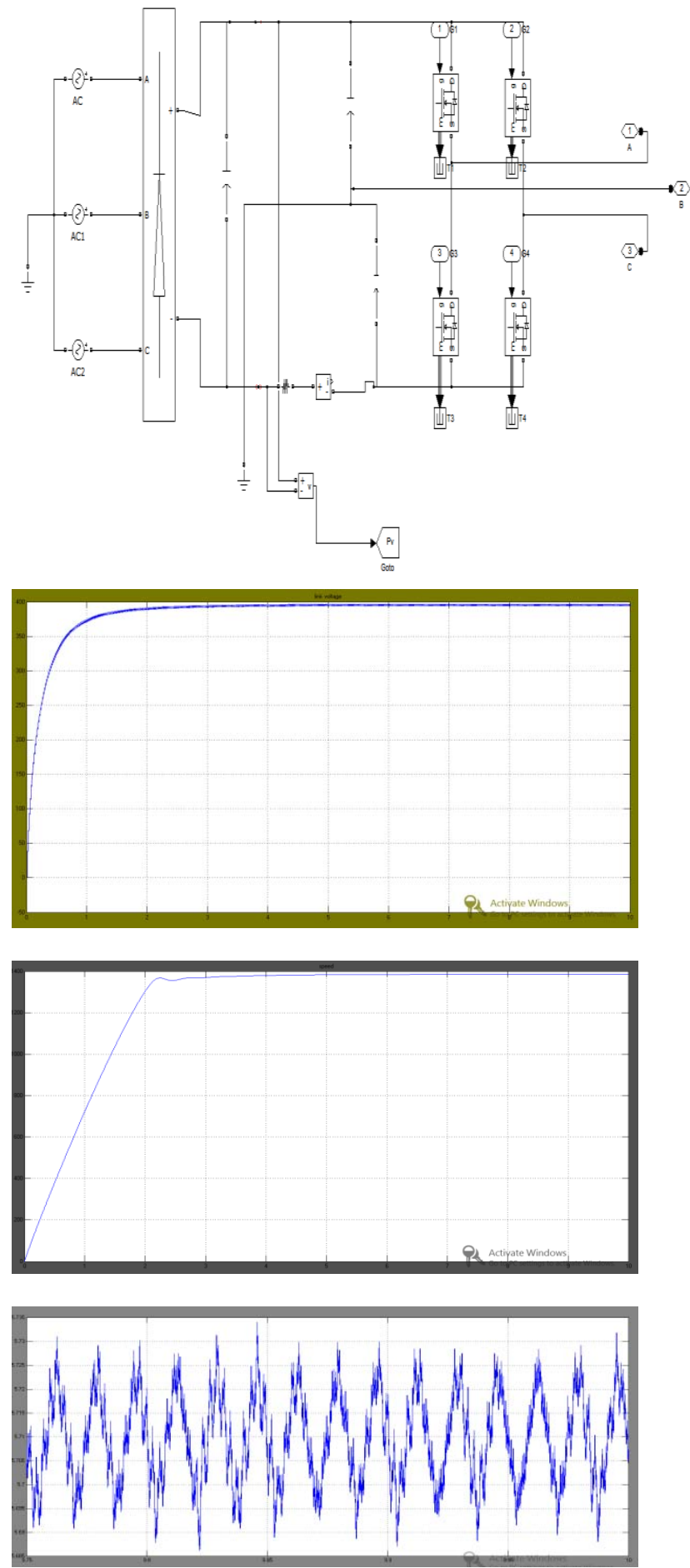

The circuit was developed and the analysis of the proposed scheme using MATLAB obtained the results below. 


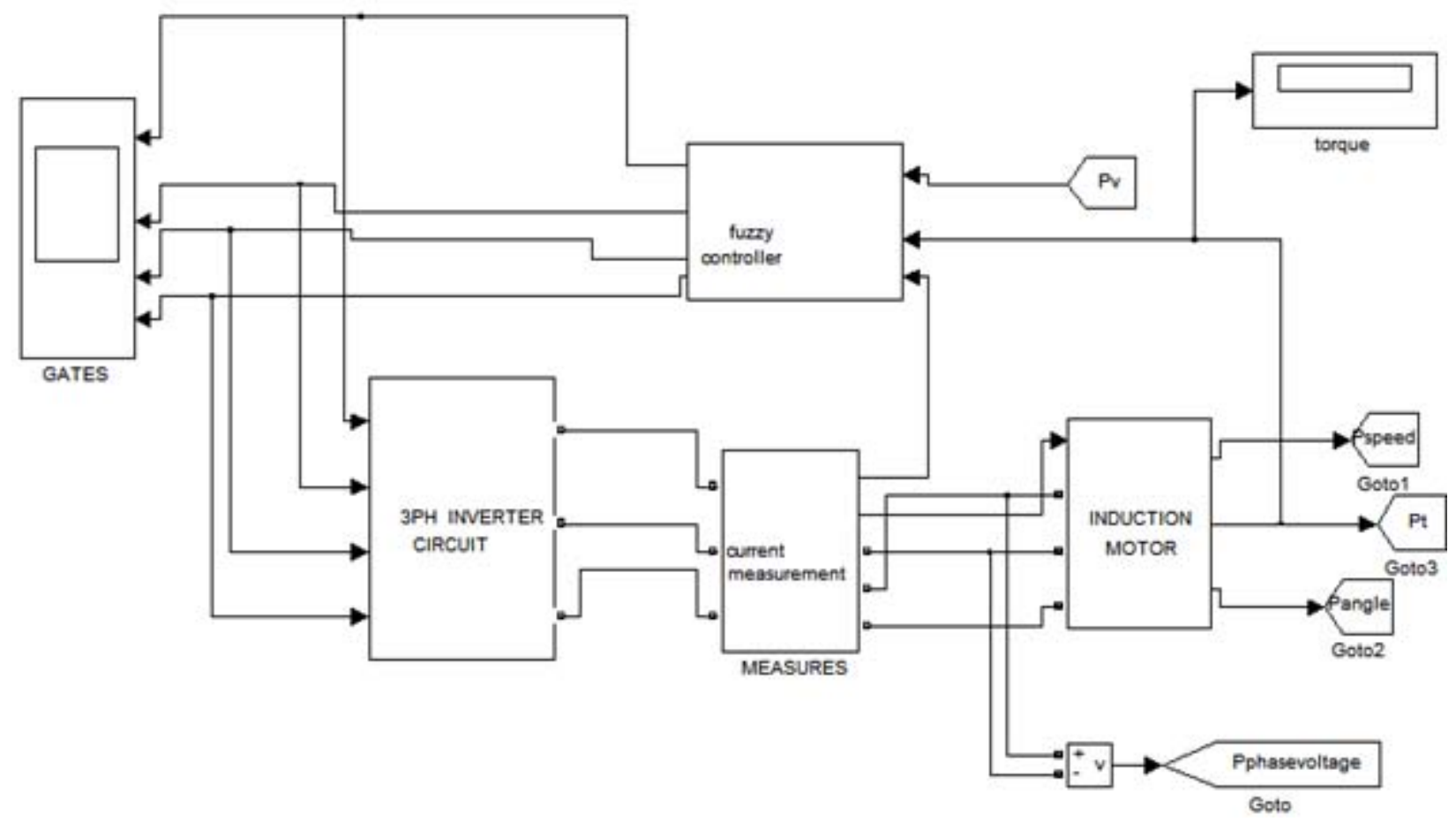

\section{Conclusion}

A simple but efficient method to control the torque ripple in induction motor is presented in the paper. The strategic selection of the control signal of inverter enables us to have direct control over motor variables.

\section{References}

[1] Simple Dynamic Overmodulation Strategy for Fast Torque Control in DTC of Induction Machines With Constant-Switching-Frequency Controller Jidin, A.; Idris, N.R.N.; Yatim, A.H.M.; Sutikno, T.; Elbuluk, M.E. IEEE Transactions on Industry Applications Year: 2011, Volume: 47, Issue: 5 Pages: 2283 - 2291,

[2] Simon.R;Geetha.A,"comparison on the performance of induction motro coontrol using fuzzy and ANFIS controllers".pp.491-495, Mar. 2013

[3] Naik.N.V;Singh S.P,”A Novel type2 fuzzy logic control of IM drive using space vector PWM," Indian conference,2012Annual IEEE . pp. 1142-1147, 2012. I

[4] Bouhoune K; Yarid K; Boucherit M.S, "Fuzzy logic based control of the single phase IM without start capacitor,'POWERENG 2013,4 $4^{\mathrm{TH}} \quad$ International conference pp. 747-752.2013

[5] Kar ,Biranchi Narayan;Mohanty,K.B;Singh.M, "Indirect vector control of Induction Motor using Fuzzy logic control," EEEIC,2011,10 ${ }^{\mathrm{TH}}$ International conference, pp. $1-42011$

[6] Asija.D,"Speed control of IM using Fuzzy-PI controller, "ICMEE.2010. Second International Conference pp. V2460-V2-463, 2010. 